\title{
A Novel Exo-Glucanase Explored from a Meyerozyma sp. Fungal Strain
}

\author{
Hsion-Wen Kuo ${ }^{1}$, Jia-Kun Zeng1, Pi-Han Wang' ${ }^{2}$, Wen-Chin Chen ${ }^{3}$ \\ ${ }^{1}$ Department of Environmental Science and Engineering, Tunghai University, Taichung, Taiwan \\ ${ }^{2}$ Department of Life Sciences, Tunghai University, Taichung, Taiwan \\ ${ }^{3}$ Department of Environmental Engineering and Health, Yuanpei University of Medical Technology, Hsinchu, \\ Taiwan \\ Email: ${ }^{*}$ hwkuo@thu.edu.tw
}

Received 8 June 2015; accepted 22 August 2015; published 25 August 2015

Copyright @ 2015 by authors and Scientific Research Publishing Inc.

This work is licensed under the Creative Commons Attribution International License (CC BY).

http://creativecommons.org/licenses/by/4.0/

(c) (i) Open Access

\begin{abstract}
Isolating cellulase-secreting microbes followed-by screening their cellulolytic activities has been an essential approach to discover novel and potential cellulases for cellulolytic industrial applications. This study was aimed to explore competitive exoglucanases by screening avicelase activities for 92 fungal strains isolated from environmental airborne-fungal-spore samples. Results showed that an isolated fungal strain numbered 58 exhibited the best avicelase activity of $0.209 \mathrm{U} / \mathrm{mL}$ when cultured for six days at pH $5.0-5.3$ and $25^{\circ} \mathrm{C}-27^{\circ} \mathrm{C}$, and was lately identified as a yeast strain of Meyerozyma sp. (96\% ITS fragment similar with Meyerozyma caribbica, HG970748). Based on amino acid sequences revealed from LC/MS/MS, the target exoglucanase was identical to 1,4beta-D-glucan cellobiohydrolases and was named $M c$-CBHI which had optimal avicelase reaction conditions of $\mathrm{pH} 5$ and $70^{\circ} \mathrm{C}$ and could remain fairly stable after 4-hr incubation at acid conditions (pH 3 - 5) or wide temperature ranges $\left(30^{\circ} \mathrm{C}-80^{\circ} \mathrm{C}\right)$. Additionally, the $\mathrm{Mc}$-CBHI $(\sim 70 \mathrm{kDa}$ and $\sim 3.6 \%$ of crude enzyme) had specific FPase and avicelase activities of $0.179 \mathrm{U} / \mathrm{mg}$ and $0.126 \mathrm{U} / \mathrm{mg}$, respectively (which were about $40 \%-50 \%$ activities of a commercial cellulase Accellerase-1000). These results demonstrated that the newly-found $M c$-CBHI could become one of potential exoglucanase resources for related cellulolytic industrial applications.
\end{abstract}

\section{Keywords}

Airborne-Fungal-Spore, Exoglucanase, 1,4-Beta-D-Glucan Cellobiohydrolases, CBHI, Meyerozyma sp.

\footnotetext{
*Corresponding author.
} 


\section{Introduction}

Cellulose of ligno-biomass is one of the most abundant natural biopolymers for many industrial products (e.g., paper, rayon, filter membrane etc.) [1], and has been considered as a major raw material for renewable biofuel production as well [2] [3]. Enzymatic hydrolysis of polymeric cellulose to monomeric sugar is a crucial step prior to sugar fermentation for renewable bioethanol production owing to slow reaction rate for complicate hydrolysis procedure coordinately-conducted by three types of cellulases, i.e., exo-glucanase (CBH) (EC 3.2.1.91 and 0.74), endo-glucanase (EG) (EC 3.2.1.4), and beta-glucosidase (BGL) (EC 3.2.1.21) [4]. In order to enhance bioethanol production rate and reduce overall manufacture cost, scientific and engineering communities have continually explored novel or modified cellulases with better hydrolyzing activity and cheaper production cost although some promising cellulases are already commercially available up to now.

Some of recent strategies for improving cost, quality, and/or quantity of cellulases have been focused on increasing enzyme stability and/or functionality (by optimizing hydrolyzing conditions or modifying enzyme component and/or structure) or expediting enzyme production titer (by optimizing fermentation conditions, mutating cellulase-secreting microbial strains, or manipulating hyper-expressing system) [5] [6]. Besides, isolation of cellulase-secreting microbial strains followed-by screening their cellulases is still an essential approach to discover novel and potential cellulases [7]-[9]. Several novel and potential cellulases have been continually discovered from some fungal strains (e.g., Schizochytrium aggregatum and Chaetomella raphigera) [10]-[12] other than the most common cellulase producers such as Aspergillus sp., Penicillium sp., and Trichoderma sp. suggesting some highly-active cellulases might stay undiscovered in diverse fungal consortium.

Fungi are ubiquitous in diverse natural environments or even in residential home. Because of their unique feature to utilize polymeric cellulose in ligno-material as carbon and energy sources for their growth, most of potential cellulases have been explored by screening cellulosic activity for crude enzymes produced from fungal strains gathered and/or isolated from diverse lignocellulose-rich samples such as soil, compost, saw dust, straw dust, decaying wood, intestinal of insects, or feces of ruminants [7] [13]-[16]. Most of fungal strains isolated from such samples were mainly belonged to the common cellulase-producing fungi of Ascomycota phylum such as Aspergillus sp., Cladosporium sp., Fusarium sp., Penicillium sp., or Trichoderma sp. [7] [16]. Additionally, because most of fungi reproduce by forming spores, large amount of airborne fungal spores produced by microfungi grown on wood or plant debris could present in outdoor air throughout the year and most of them could be allergenic [17]; whereas, some of them may germinate potential cellulase-secreting fungal strains as well. Nevertheless, fungal spores in air still have seldom been screened for cellulosic activities.

Besides, it has been suggested that hydrolyses activity for mixtures of different types of cellulases was higher than the sum of activities for each component acting alone, indicating the components were acting on cellulose synergistically [18] [19]. For synergistic formulation of cellulases conducted in Taiwan, availability of indigenous exo-glucanase (or cellobiohydrolases, $\mathrm{CBH}$ ) has been relatively less than endo-glucanase (EG) and betaglucosidase (BGL). Searching novel and potential CBH for local or even global applications has been essential for bioethanol industrial. The research goal of this study was to screen and identify novel/potential exo-glucanase secreted by fungal strains isolated from environmental aerosol samples. Optimal reacting conditions and specific activities of newly-found exo-glucanase were also determined to evaluate its compatibility.

\section{Materials and Methods}

\subsection{Sample Collection and Fungal Strain Isolation}

Fungal spores were collected from several locations of central Taiwan area during July-December of 2011 by pumping air into $0.005 \%$ Triton-X100 buffer (at a flow rate of $300 \mathrm{~L} / \mathrm{min}$ for 10 minutes) with a Coriolis ${ }^{\circledR} \mu$ Air Sampler (Bertin Technologies, France). Serially diluted air samples were spread on potato dextrose agar plate (PDA, Difco, USA) and incubated at $25^{\circ} \mathrm{C}$ for fungal strain germination and isolation. Isolated fungal strains (numbered from $\# 1$ to $\# 92$ in this study) were stored at $-20^{\circ} \mathrm{C}$ for follow-up screening for potential cellulases.

Each of the isolated fungal strains or a benchmark strain of Trichoderma reesei from culture stocks were individually recovered by culturing on PDA plates at $\mathrm{pH} \sim 5.6$ and room temperature $\sim 27^{\circ} \mathrm{C}$; and then, a $\sim 5 \mathrm{~mm}^{3}$ 7-day-old mycelia block of each strain was re-cultured at $\mathrm{pH} \sim 5.3$ and $\sim 27^{\circ} \mathrm{C}$ on modified MR plate (MandelReese medium without peptone, MR-P) with $2 \% \alpha$-cellulose (each liter had $1.4 \mathrm{~g}\left(\mathrm{NH}_{4}\right)_{2} \mathrm{SO}_{4}, 0.8 \mathrm{~mL}$ of $6 \mathrm{M}$ urea, $2 \mathrm{~g} \mathrm{KH}_{2} \mathrm{PO}_{4}, 0.34 \mathrm{~g} \mathrm{CaCl}_{2}, 0.3 \mathrm{~g} \mathrm{MgSO}_{4} \cdot 7 \mathrm{H}_{2} \mathrm{O}, 0.00005 \mathrm{~g} \mathrm{FeSO}_{4} \cdot 7 \mathrm{H}_{2} \mathrm{O}, 0.000016 \mathrm{~g} \mathrm{MnSO}_{4} \cdot 7 \mathrm{H}_{2} \mathrm{O}$, $0.000014 \mathrm{~g} \mathrm{ZnSO}_{4} \cdot 7 \mathrm{H}_{2} \mathrm{O}$, and $0.00002 \mathrm{~g} \mathrm{CoCl}_{2} \cdot 6 \mathrm{H}_{2} \mathrm{O}$, and $20 \mathrm{~g}$ agar). Consequently, 6 of $\sim 5 \mathrm{~mm}^{3} 7$-day-old 
mycelia blocks from the MR-P plate were transferred into 100-mL MR-P liquid medium (duplicate $\mathrm{n}=2$ for environmental isolates and $n=6$ for $T$. reesei) and cultured for another 7 days by shaking at 150-rpm to harvest crude enzyme (secretome) from each of isolated fungal strains and the benchmark strain T. reesei for following cellulolytic activity tests and enzyme characteristics assessments.

\subsection{Screening Potential Cellulases Based on Activity Tests}

The crude enzymes (or secretomes) produced from fungal strains were tested for cellulolytic activities using pNPG $(5 \mathrm{mM})$, CMC $(1 \%, \mathrm{w} / \mathrm{v})$, and avicel $(1 \%, \mathrm{w} / \mathrm{v})$ as substrates in order to screen potential cellulases. Additionally, FPase activity was extra conducted for potential exoglucanase using a piece of $3 \mathrm{mg}$ filter paper as substrate (6mm-diameter circle shape cut by paper puncher) in order to compare with other previous studies. The enzymatic $p$ NPGase activity was determined based on amount of $p$-nitrophenol $(p N P)$ released from $5 \mathrm{mM}$ $p$ NPG after 5 -min reaction at $55^{\circ} \mathrm{C}$ and $\mathrm{pH} 5$ by measuring absorbance at a wavelength of $405 \mathrm{~nm}$ in a microtiter plate reader (SpectraMax M5e, Molecular Devices, USA). Additionally, the CMCase, avicelase, and FPase activities were assessed by measuring reducing sugar concentration at a wavelength of $550 \mathrm{~nm}$ using the di-nitrosalicylic acid (DNS) method after reacting at $55^{\circ} \mathrm{C}$ and $\mathrm{pH} 5$ for 10 minutes (for CMCase) or 60 minutes (for avicelase and FPase) in $50 \mathrm{mM}$ sodium acetate buffer. All the cellulolytic activities were represented as $\mathrm{U} / \mathrm{mL}$ ( $\mu \mathrm{mol}$ of product, i.e., $p \mathrm{NP}$ or reducing sugar, produced within 1 minute per $\mathrm{mL}$ of enzyme).

\subsection{Optimal Cultivation Conditions}

Optimal cultivation conditions for the potential fungal strains (i.e., strains \#58, \#60, and \#71) (original sample names: 13-5-2-2, 13-6-2A, and THU4) were investigated by culturing the fungal strains at two temperature levels of $25^{\circ} \mathrm{C}$ or $30^{\circ} \mathrm{C}$ (using thermal-control water bath) and three $\mathrm{pH}$ values of 5,6 , or 7; and, followed by avicelase activity assessments for the fungal secretomes at six temperature levels (i.e., $30^{\circ} \mathrm{C}, 40^{\circ} \mathrm{C}, 50^{\circ} \mathrm{C}, 60^{\circ} \mathrm{C}$,

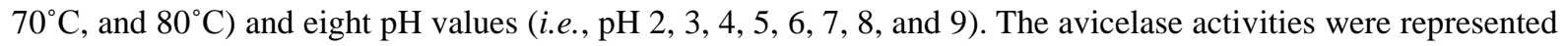
as relative activity (\%) by comparing each activity with the highest activity measured throughout the assessments and used to determine the optimal cultivation conditions and the optimal avicelase reaction conditions.

In addition, $\mathrm{pH}$ stability and thermostability for the most potential crude enzyme were also resolved by incubating the fungal secretome at eight different $\mathrm{pH}$ levels $(\mathrm{pH} \mathrm{2,} \mathrm{3,} \mathrm{4,} \mathrm{5,} \mathrm{6,} \mathrm{7,} \mathrm{8,} \mathrm{and} \mathrm{9)} \mathrm{or} \mathrm{six} \mathrm{temperature} \mathrm{levels}$ $\left(30^{\circ} \mathrm{C}, 40^{\circ} \mathrm{C}, 50^{\circ} \mathrm{C}, 60^{\circ} \mathrm{C}, 70^{\circ} \mathrm{C}\right.$, and $80^{\circ} \mathrm{C}$ ) for four hours and followed by avicelase activity test under optimal reaction conditions. All measured avicelase activities were also converted to relative activity (\%) by deviding each activity with the highest activity measured throughout the assessments for assessing enzyme stability.

\subsection{Identification of Potential Cellulase-Secreting Fungal Strain}

Genomic DNA of the potential fugal strain \#58 was purified from 6-day cultured fungal mycelia using a commercial extraction kit (Genomic DNA Extraction Kit, Fast ID, Genetic ID NA, IA, USA). Identification of the fungal strain \#58 was conducted by comparing gene sequences of internal transcribed spacer (ITS) region that was PCR-amplified using ITS1 forward primer (TCC GTA GGT GAA CCT GCG G) and ITS4 reverse primer (TCC TCC GCT TAT TGA TAT GC). Each $25-\mu$ l PCR reaction contained $12.5 \mu \mathrm{l}$ of Master Mix (EmeraldAmp ${ }^{\circledR}$ MAX HS PCR Master Mix, TaKaRa, Shiga, JP), $1 \mu$ of each $10 \mu \mathrm{M}$ forward and reverser primers (final concentrations were $400 \mathrm{nM}$ ), $8.5 \mu \mathrm{l}$ of PCR-grade water, and $2 \mu \mathrm{l}$ of the fungal DNA extract. A PCR reaction were run in a thermal cycler (MyCycler ${ }^{\mathrm{TM}}$, Bio-Rad, Hercules, CS, USA) based on the following program: 5 min at $94^{\circ} \mathrm{C}$; followed by 35 cycles at $94^{\circ} \mathrm{C}$ for $1 \mathrm{~min}, 50^{\circ} \mathrm{C}$ for $1 \mathrm{~min}, 72^{\circ} \mathrm{C}$ for $1 \mathrm{~min}$; and finally $10 \mathrm{~min}$ at $72^{\circ} \mathrm{C}$.

PCR amplicon was purified from agarose gel and sent for sequencing at MissionBio Co (Taipei, TW). Sequencing result was compared with NCBI database to determine fugal genus and species. The ITS fragments of the fungal strain \#58, the first matched fungal species, and some closely related fungal strains were aligned by ClustalX method [20] and phylogenetic trees were constructed by neighbor-joining method and displayed with TreeView program [21].

\subsection{PAGE for Target Exo-Glucanase Identification and Quantification}

Crude enzyme concentration was determined based on Bio-Rad Protein Assay using BSA (bovine serum albu- 
min) as calibration standards (Bio-Rad, USA). For better visualization on PAGE (polyacrylamide gel electrophoresis), the crude enzyme was further concentrated by lyophilisation for 4 hours and followed by dialyses for 3 hours to eliminate salts and metals in the MR culture medium using 3500 MWCO SnakeSkin ${ }^{\mathrm{TM}}$ Dialysis Tubing (Thermo Fisher Scientific, Life Technologies, Waltham, MA, USA).

Native PAGE and SDS (sodium dodecylsulfate) PAGE were performed based on the protocols suggested by Hoefer's Protein Electrophoresis Applications Guide [22]. Briefly, the concentrated crude enzyme was directly loaded in a $10 \%$ native-PAGE or first denatured by heating for 3 minutes at $100^{\circ} \mathrm{C}$ in a $2 \times$ protein treatment buffer (containing $0.125 \mathrm{M}$ Tris-HCl, 4\% SDS, 20\% glycerol, $0.2 \mathrm{M} \mathrm{DTT}$, and $0.02 \%$ bromophenol blue) and then loaded in a $10 \%$ SDS-PAGE gels to conduct electrophoresis $(90 \mathrm{~V}$ for 30 minutes and then $140 \mathrm{~V}$ for 90 minutes). Followed by electrophoresis, the gel was stained with Coomassie blue R250 to view the native-PAGE or SDS-PAGE images. For zymographic assessment, the native-PAGE gel was further merged in a MUC solution (pH 5) and incubated at $70^{\circ} \mathrm{C}$ and $20 \mathrm{rpm}$ for 30 minutes and subsequently observed under UV light. Exoglucanase activity was visible as clear light bands against a black background.

The bands of target exoglucanase observed on the SDS-PAGE were cut and purified from gel and analyzed for amino acid sequences at a Proteomics Core Laboratory (located in the Agricultural Biotechnology Center of Academia Sinica, Taipei, Taiwan) using Applied Biosystems Procise ${ }^{\circledR}$ Protein Sequencer model 494 (Applied Biosystems, USA). The sequenced amino acid fragments were compared with sequences from the NCBI protein database using a program of Protein BLAST.

Additionally, proportion of the target exoglucanase within the crude enzyme produced from the fungal strain \#58 was estimated by using another 10\% SDS-PAGE with different amounts of BSA as standards (i.e., 0.5, 1, 2, 3,5 , and $10 \mu \mathrm{g} \mathrm{BSA}$ ). A calibration curve was constructed based on correlations between protein concentrations and image intensities of protein on the PAGE; and, was used to calculate the quantity of the target exoglucanase. Specific FPase and avicelase activities were determined afterward according to the exoglucanase concentration evaluated from the above-mentioned approach.

\section{Results and Discussion}

\subsection{Fungal Strains Culturing and Cellulosic Activities Screening}

During 7-day cultivation for the fungal strains isolated from environments together with the benchmark strain $T$. reesei, avicelase activities of the fungal-secreted crude enzymes (for indicating exo-glucanase titers) increased gradually and reached highest levels mostly around 6 days (Figure 1). CMCase and pNPGase activities also reached highest levels after 5 - 7 days cultivation (time course activity profile data not showed). Among the 92

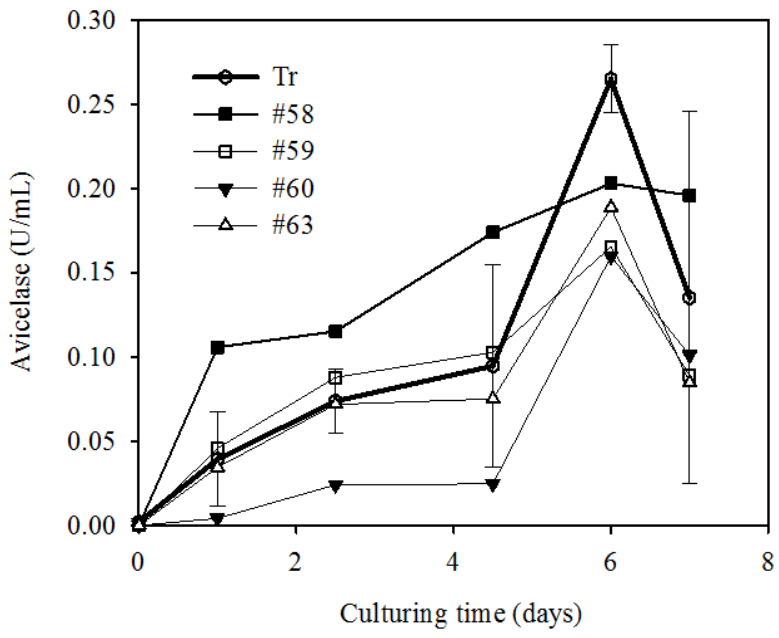

Figure 1. Time-course profiles of avicelase activities for $T$. reesei $(n=6)$ and fungal strains \#58, \#59, \#60, and \#63 ( $=2$ ) during 7-day cultivation at $\mathrm{pH} \sim 5.3$ and room temperature $\sim 27^{\circ} \mathrm{C}$. 
environmental isolates, most of them had highest avicelase activities less than $0.1 \mathrm{U} / \mathrm{mL}$ while only some fungal strain such as \#58, \#59, \#60, and \#63 showed more significant avicelase activities ( $>0.1 \mathrm{U} / \mathrm{mL}$ ) as illustrated in Figure 1. The avicelase activities for fungal strain \#58 increased more significantly (up to about $0.106 \mathrm{U} / \mathrm{mL}$ ) than other fungal strains only after about 1 day cultivation and reached a highest level of $0.209 \mathrm{U} / \mathrm{mL}$ at $6^{\text {th }}$-day making it one of the top candidates for finding novel potential exoglucanase.

The highest avicelase, CMCase, and pNPGase activities for each fungal strain during 7-day cultivation were selected for further comparisons to screen potential cellulases (Figure 2). Most of the fungal strains had notable CMCase (endo-glucanase) activities and few of them even had higher CMCase activity than that for $T$. reesei (Figure 2(b)). Besides, few fungal strains had pNPGase (beta-glucosidase) activities (Figure 2(c)). In addition, six out of 92 fungal strains had avicelase activities higher than $0.1 \mathrm{U} / \mathrm{mL}$ (i.e., strains \# 26, \#58, \#59, \#60, \#63, and \#71) as T. reesei had an avicelase activity of $0.27 \pm 0.02 \mathrm{U} / \mathrm{mL}$ (Figure 2(a)). Beside the results from tube activity assay mentioned above, MUC zymogram was also used to preliminarily screen exoglucanase activity for these six strains. MUC zymogram results showed only strains \#58, \#60, and \#71 had significant MUCase activities (images showed in Figure 2(a)). Therefore, the fungal strain \#58, \#60, and \#71 were selected for further assessing their optimal culturing conditions and optimal avicelase reaction conditions.

\subsection{Optimal Culturing Conditions, Enzyme Reaction Conditions, and Enzyme Stability}

Fungal strain $\# 58$ grew at a $\mathrm{pH}$ of 5 and a temperature of $25^{\circ} \mathrm{C}$ exhibited better avicelase activity than other culturing conditions (Figure 3). Higher pH values at 6 or 7 and higher temperature at $30^{\circ} \mathrm{C}$ resulted in less avicelase activity. In addition, optimal enzyme reaction conditions for secretome of the fungal strain \#58 (produced at $\mathrm{pH} 5$ and $25^{\circ} \mathrm{C}$ ) were in a pH range of $4-6$ and a temperature range of $60^{\circ} \mathrm{C}-80^{\circ} \mathrm{C}$ (Figure 3(a)). Furthermore,

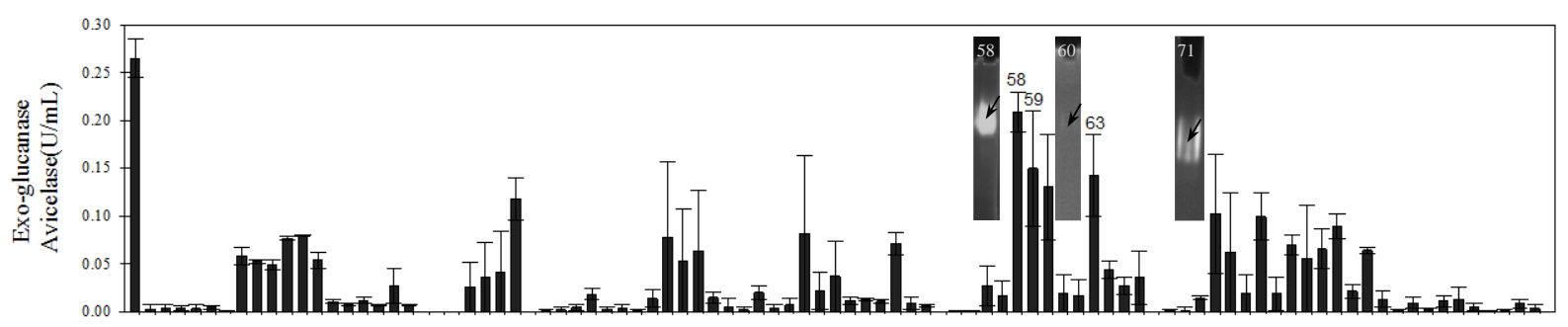

(a)

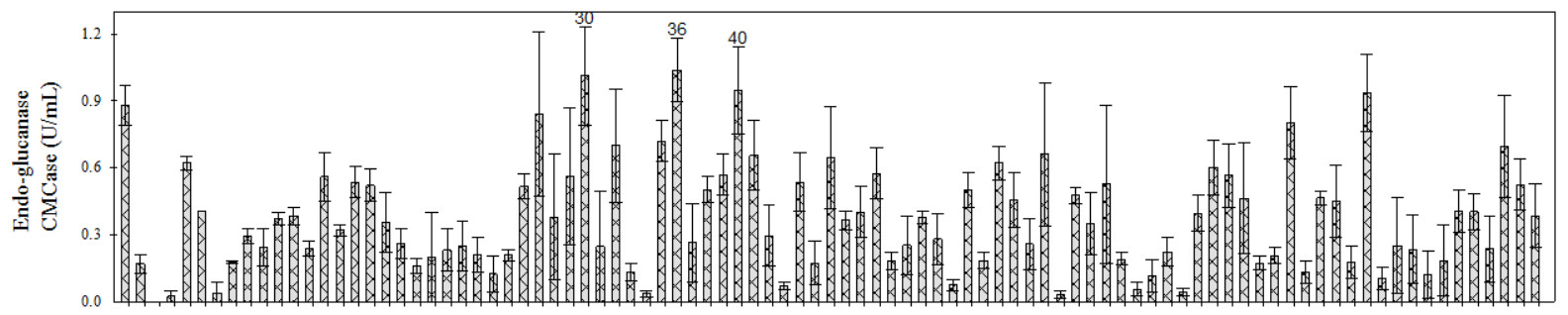

(b)

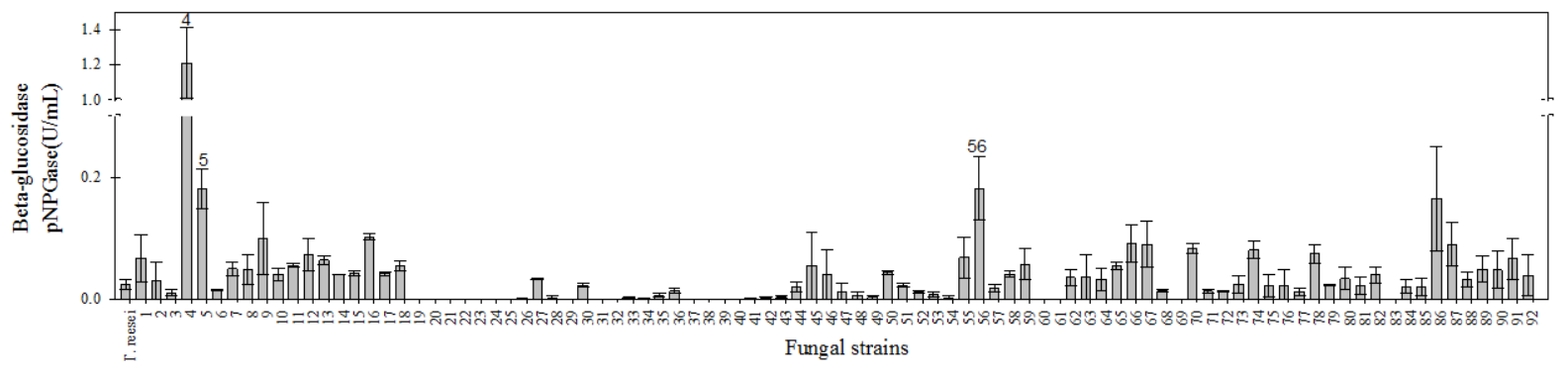

(c)

Figure 2. Avicelase (a); CMCase (b); and pNPGase (c) activities for T. reesei and 92 fungal strains from environments. Top three strain numbers were indicated. 

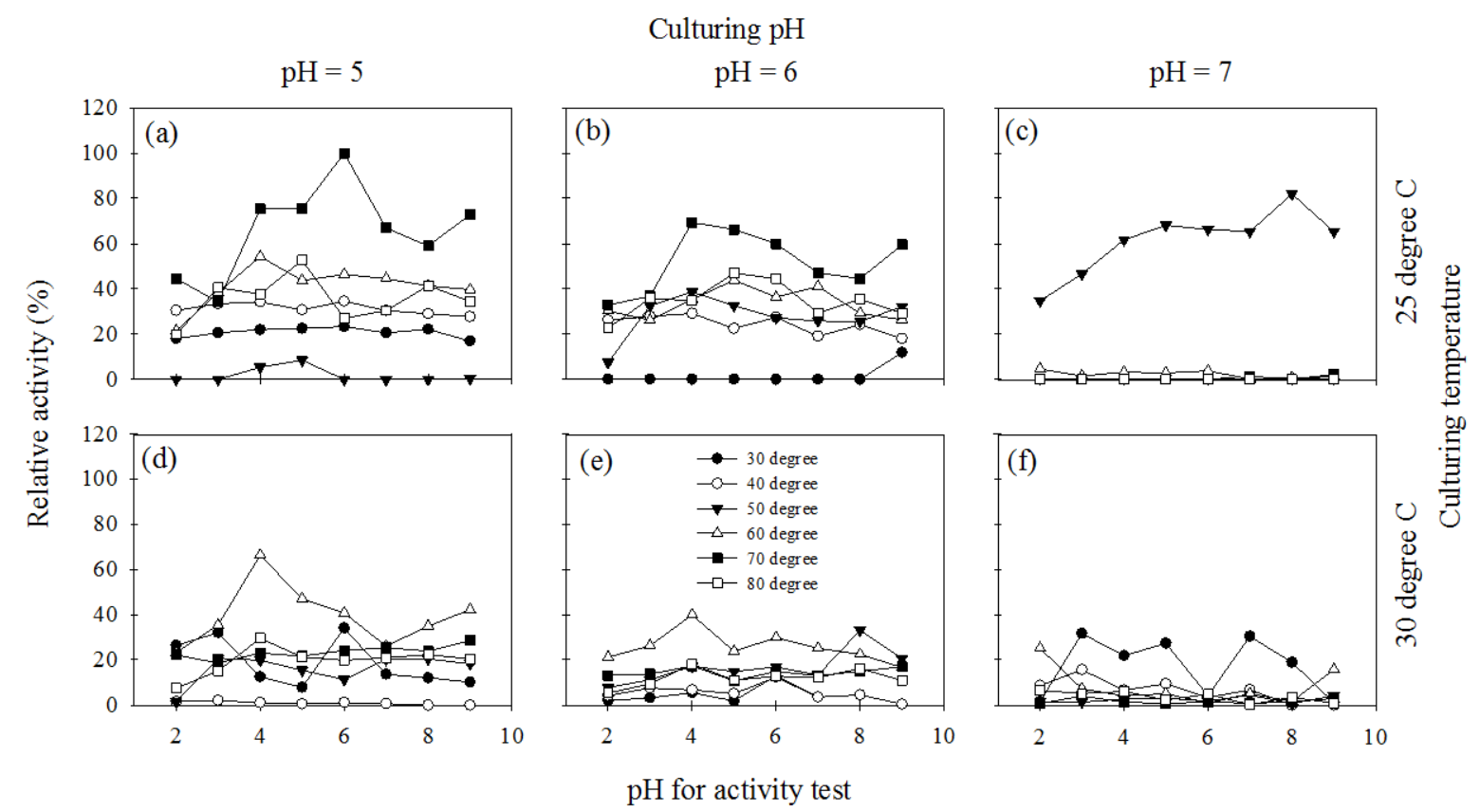

Figure 3. Optimal growth conditions of fungal strains \#58 were determined based on assessments of relative activity (\%) of crude enzymes produced at three pH levels of 5 (a) (d); 6 (b) (e); or 7 (c) (f) and two incubation temperatures of 25 (a) (b) (c) or $30^{\circ} \mathrm{C}$ (d) (e) (f). Avicelase activity tests were conducted under 8 different $\mathrm{pH}$ levels (i.e., 2, 3, 4, 5, 6, 7, 8, or 9) and 6 different reaction temperatures (i.e., $30^{\circ} \mathrm{C}, 40^{\circ} \mathrm{C}, 50^{\circ} \mathrm{C}, 60^{\circ} \mathrm{C}, 70^{\circ} \mathrm{C}$, or $80^{\circ} \mathrm{C}$ ).

the exo-glucanase activity for the fungal strain \#58 remained more stable at acid conditions ( $\mathrm{pH} 3$ - 5) than at base conditions (Figure 4(a)); and, could stay rather stable over a wide temperature range even at high temperature of $70^{\circ} \mathrm{C}-80^{\circ} \mathrm{C}$ (Figure 4(b)). By considering enzyme stability, optimal avicelase reaction conditions were lastly determined as a $\mathrm{pH}$ of 5 and a temperature of $70^{\circ} \mathrm{C}$ for the secretome of strain \#58.

During 7-day cultivations for the 92 isolated fungal strains, the culturing $\mathrm{pH}$ was around 5.3 for the MR-P medium and incubation temperature was round $27^{\circ} \mathrm{C}$ for room temperature of the laboratory with air conditioner. These culturing conditions were close to those culture conditions determined for the fungal strain \#58 ( $\mathrm{pH} 5$ and $25^{\circ} \mathrm{C}$ ); and, preliminarily screening results indicated the strain \#58 was the most competitive candidate for exploring potential exo-glucanase. The avicelase activity gained during screening $(0.209 \mathrm{U} / \mathrm{mL})$ was even higher than that at $\mathrm{pH} 5$ and $25^{\circ} \mathrm{C}(0.145 \mathrm{U} / \mathrm{mL})$ for optimal culturing conditions assessment. Furthermore, the screening conditions might not suitable for other fungal strains as the strains \#60 and \#71 had better avicelase activities when cultured at $25^{\circ} \mathrm{C}$ and at $\mathrm{pH} 7$ and 6, respectively (data not showed). Nevertheless, the highest avicelase activities for strain \#60 (relative activity 50.3\% under optimal culturing and enzyme reaction conditions) and \#71 (94.2\%) were still lower than that for the stain \#58 (100\%). Hence, only the results for the strain \#58 were showed in the Figure 3. When the fungal strain $\# 58$ was cultured at $30^{\circ} \mathrm{C}$, the avicelase activities of harvested secretomes were typically less than $60 \%$ of the highest avicelase activities observed at $25^{\circ} \mathrm{C}$ and $\mathrm{pH} 5$ suggesting lower temperature around $25-27^{\circ} \mathrm{C}$ and $\mathrm{pH}$ about 5-5.3 were more suitable for exo-glucanase production from the strain \#58 than at $30^{\circ} \mathrm{C}$ and $\mathrm{pH}$ 6-7.

Interestingly, as the fungal strain $\# 58$ was cultured at $30^{\circ} \mathrm{C}$, optimal avicelase reaction conditions of the crude enzyme appeared to be shifted from $\mathrm{pH} 6$ and $70^{\circ} \mathrm{C}$ (Figure 3(a) and Figure 3(b)) to $\mathrm{pH} 4$ and $60^{\circ} \mathrm{C}$ (Figure 3(d) and Figure 3(e)). Besides, when it was cultured at $\mathrm{pH} 7$, the optimal enzyme reaction conditions (i.e., $\mathrm{pH} 7$ - 8 and $30^{\circ} \mathrm{C}-50^{\circ} \mathrm{C}$, Figure 3(c) and Figure 3(f)) were different from those for the secretomes harvested at $\mathrm{pH} 5$ and 6 (i.e., $\mathrm{pH} 4-6$ and $60^{\circ} \mathrm{C}-70^{\circ} \mathrm{C}$, Figure 3(a), Figure 3(b), Figure 3(d), and Figure 3(e)). The results indicated that various types of enzymes (e.g., isozymes) with diverse characteristics might produce from the strain \#58 when it was cultured under different $\mathrm{pH}$ and temperature conditions. A previous study had suggested that productions of lignolytic enzymes from a basidiomycetous fungal strain were dissimilar under different culture conditions [23]; and, another report had indicated that Aspergillus fumigates Z5 produced different proteins after 


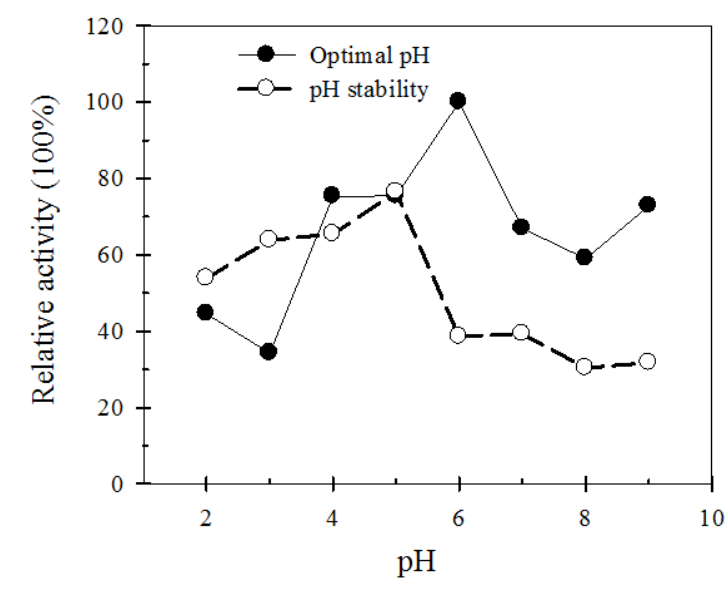

(a)

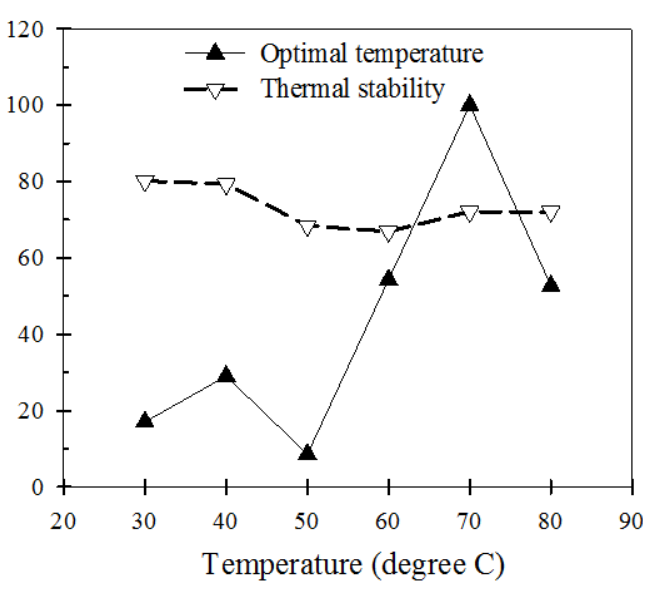

(b)

Figure 4. (a) Optimal reaction $\mathrm{pH}$ and temperature and (b) $\mathrm{pH}$ and thermal stabilities of the crude enzymes for fungal strain \#58.

cultivation with various carbon sources (i.e., glucose, avicel, and rice straw) [24]. It was surmised some cellulolytic enzymes might not be produced or might just be produced at very low level under inappropriate culturing conditions.

Given that some other common cellulase-secreting fungi (e.g., Aspergillus sp., Fusarium sp., Penicillium sp., and Trichoderma sp.) typically having optimal culturing $\mathrm{pH}$ level of about 5 and optimal temperature of around $28^{\circ} \mathrm{C}-30^{\circ} \mathrm{C}$, the fungal strain \#58 isolated in this study seemed more suitable to be cultured under low pH of 5 as well but at lower temperature of $25^{\circ} \mathrm{C}-27^{\circ} \mathrm{C}$. Besides, crude enzyme harvested from the strain \#58 had better avicelase activities when reacted at pH 5 that was similar to most of other exo-glucanases (Table 1); but, had an optimal reaction temperature of $70^{\circ} \mathrm{C}$ which was much higher than typical reaction temperature of $50^{\circ} \mathrm{C}-60^{\circ} \mathrm{C}$ for other exo-glucanases. In addition, the strain \#58 secretome remained stable at high temperatures of $60^{\circ} \mathrm{C}$ $80^{\circ} \mathrm{C}$ for at least four hours which was seldom found for many of general cellulases from fungi. Some of these unique features inferred that the fungal strain \#58 might different from the common cellulase-secreting fungi and some new exo-glucanases might be able to be found from this potential fungal strain.

\subsection{Fungal Strain and Exo-Glucanase Identification}

The internal transcribed spacer (ITS) region of the fungal strain \#58 was PCR amplified and further sequenced for fungal type identification. Sequencing result of the ITS fragment indicated that the fungal strain \#58 was closely matched with a yeast Meyerozyma caribbica (96\% similarity, NCBI accession number HG970748) in the Saccharomycetes class of Ascomycota phylum and formed a noticeable group together with Candia sp. and Pichia sp. in a phylogenetic tree (Figure 5).

The Meyerozyma sp. had been identified in yeast population of olive mill wastes [25] and had been found capable of improving maize productivity and minimizing requisite chemical fertilization [26]. Besides, a yeast strain of Meyerozyma caribbica MG20W had been isolated from plant rhizosphere soil and its complete genome had recently been sequenced [27]. These previous studies well supported that Meyerozyma sp. could ubiquitously present in some environments and might be able to secrete glycosidase, hydrolase, or specific cellulase.

Currently, a beta-1,3 exo-glucanase had been reported for the yeast Meyerozyma caribbica [28] which was belong to the glycosyl hydrolase (GH) 5 family (EC 3.2.1.58). But, no beta-1,4 exo-glucanase has been discovered from this yeast up to the best of our understanding. The avicelase activity observed for the secretomes produced from the fungal strain \#58 isolated in this study indicated this Meyerozyma sp. yeast might capable of secreting beta-1,4 exo-glucanase.

The target exoglucanase of the Meyerozyma sp. strain \#58 had a molecular size of about $70 \mathrm{kDa}$ based on the SDS-PAGE analyses for the enzyme purified from bands observed and cut from the native-PAGE (Figure 6(a) and Figure 6(c)). Besides, the target exoglucanase showed notable activity on the MUC zymogram like a commercial enzyme C1.5 L did (Figure 6(b)). It appeared that specific activity of C1.5L was higher than that of the 


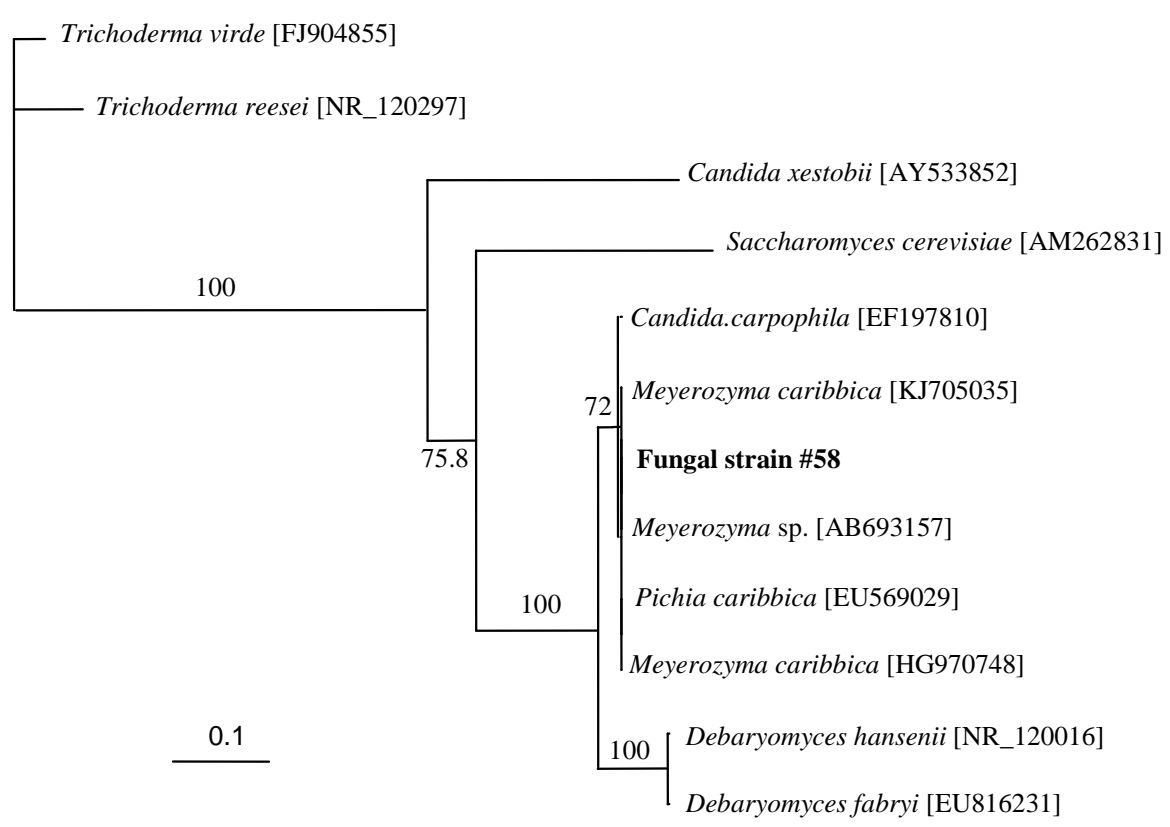

Figure 5. A phylogenetic tree showed fungal strain \#58 belongs to the cluster of Meyerozyma sp.

Table 1. Comparisons of optimal reaction $\mathrm{pH}$ and temperature for activity tests of exo-glucanases for the exo-glucanases.

\begin{tabular}{cccc}
\hline Fungi & Optimal $\mathrm{pH}$ & Optimal temp $\left({ }^{\circ} \mathrm{C}\right)$ & Reference \\
\hline Aspergillus sp. & 5.0 & 70 & {$[31]$} \\
Penicillium brefeldianum & 4.8 & - & {$[7]$} \\
Penicillium decumbens & 4.2 & 50 & {$[31]$} \\
Trichoderma reesei & 4.0 & 50 & {$[32]$} \\
& 5.0 & 55 & {$[33]$} \\
Fungal strain \#58 & $4.0-5.0$ & 55 & {$[34]$} \\
\hline
\end{tabular}

strain \#58 while C1.5L required smaller amount of enzyme than the strain \#58 to exhibit strong image intensity like observed on the native-PAGE and MUC-zymogram (Figure 6(a) and Figure 6(b)).

The target exoglucanase of the Meyerozyma sp. strain \#58 was further extracted from the SDS-PAGE and subsequently analyzed for the amino acid sequences using LC/MS/MS. Two amino acid fragments from sequencing results (i.e., YSGTCDPDGCDFNPYR and AGAKYGTGYCDSQCPR) were identical with 1,4-betaD-glucan cellobiohydrolases (CBHI) from Aspergillus aculeatus (NCBI accession number O59843) [29]. Two amino acid fragments revealed from LC/MS/MS demonstrated the target $M c-C B H I$ was beta-1,4 exo-glucanase belonged to glycosyl hydrolase family 7 (GH7). The two fragments were also extensively found in some cellobiohydrolases of other strains including Aspergillus parasiticus SU-1 (KJK66765.1), Acytostelium subglobosum LB1 (GAM28417.1), Chaetomium senegalense (CDF76452), Lophodermium sp. ZY-2014 (AIJ50313.1), Penicillium roqueforti FM164 (CDM37977.1), or Rhizopus stolonifer var. reflexus (AHI87690.1) etc. within the NCBI database. These results demonstrated that the target exoglucanase of the Meyerozyma sp. strain \#58 belonged to beta-1,4 exo-glucanase (or 1,4-beta-D-glucan cellobiohydrolases, CBHI) (EC 3.2.1.91) and was lately named $M c$-CBHI. 

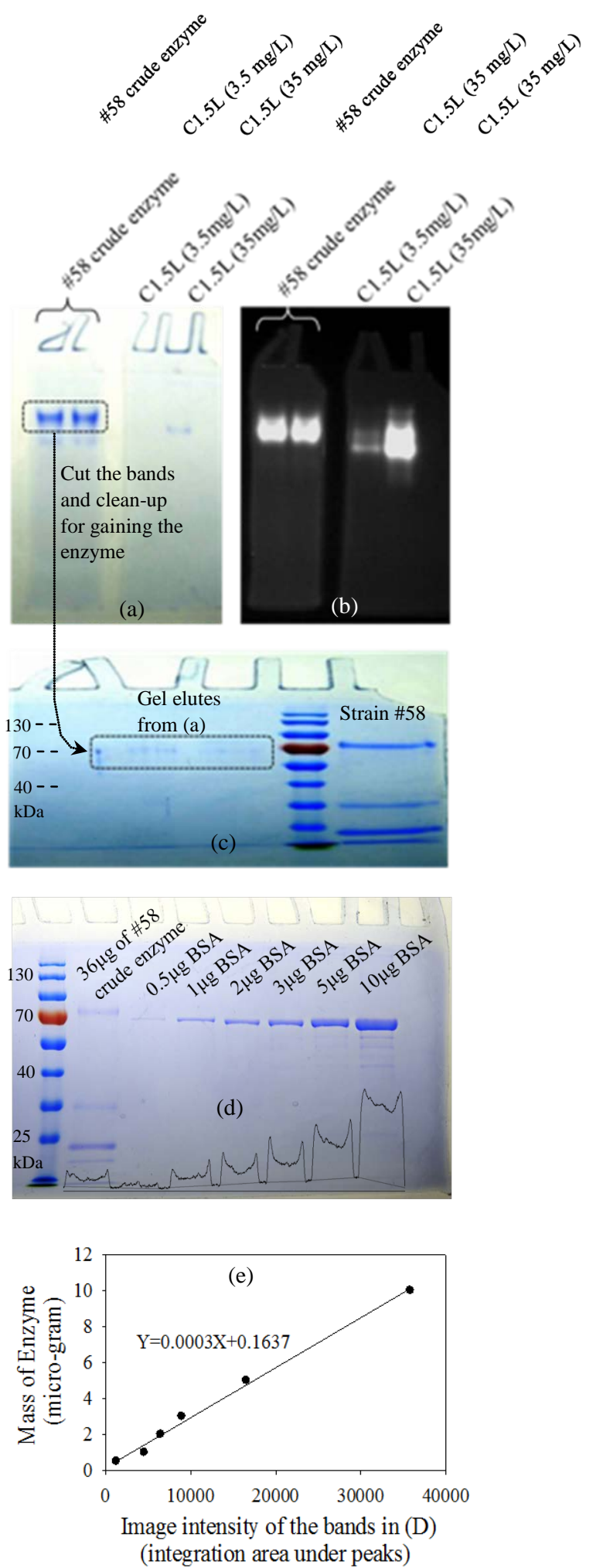

Figure 6. Native PAGE (a), MUC zymogram (b); SDS PAGE (c) showed target exo-glucanase $\mathrm{Mc}$-CBHI had a size of around $70 \mathrm{kDa}$ and had significant exo-glucanase activity (using MUC as substrate). Proportion of $\mathrm{Mc}$-CBHI in the crude enzyme mixture produced from fungal strain \#58 was estimated using BSA as standards (d) and (e). 


\subsection{Specific FPase and Avicelase Activities of $M c$-CBHI}

The proportion of the $\mathrm{Mc}$-CBHI within the crude enzyme produced from the strain \#58 was further determined by comparing band intensity of the Mc-CBHI on the SDS-PAGE with those for known amount of BSA. Image intensities for different amount of BSA were well correlated with the quantity of BSA (Figure 6(e)) and the target exoglucanase observed on the SDS-PAGE was estimated to be about $1.3 \mu \mathrm{g}$ (or $1.66 \mathrm{mg} / \mathrm{mL}$ ) which was approximately 3.6\% of total crude enzyme (i.e., $36 \mu$ g on SDS-PAGE or $45.93 \mathrm{mg} / \mathrm{mL}$ ) harvested from the Meyerozyma sp. strain \#58.

The specific FPase and avicelase activities of the Mc-CBHI became $0.179 \mathrm{U} / \mathrm{mg}$ and $0.126 \mathrm{U} / \mathrm{mg}$ calculated from the volumetric activity of $0.376 \mathrm{U} / \mathrm{mL}$ and $0.209 \mathrm{U} / \mathrm{mL}$ (Table 2); which were close to those for $T$. reesei CDU-11 (i.e., $0.25 \pm 0.05$ and $0.11 \pm 0.03 \mathrm{U} / \mathrm{mg}$, respectively) and were about $40 \%-50 \%$ of a commercial cellulase Accellerase-1000 (i.e., $0.44 \pm 0.01$ and $0.25 \pm 0.01 \mathrm{U} / \mathrm{mg}$ ) [30]. These results indicated that of the newly-found $\mathrm{Mc}$-CBHI was potentially competitive. If enzyme quality and quantity could be further improved by optimizing fermentation conditions or enzyme purification, the Mc-CBHI could be considered as a potential exoglucanase resource for related cellulolytic industrials.

\section{Conclusion}

In summary, a novel exoglucanase named Mc-CBHI was explored from a Meyerozyma sp. fungal strain \#58 (96\% identical with a yeast strain of Meyerozyma caribbica based on ITS fragment comparison) which was isolated

Table 2. Comparisons of the exo-glucanase activity using FPase and avicelase for some various fungal strains from previous reports and this study.

\begin{tabular}{|c|c|c|c|}
\hline Fungi & FPase $(\mathrm{U} / \mathrm{mL})$ & Avicelase (U/mL) & Reference \\
\hline Aspergilllus niger & $0.123(0.006-0.330)$ & - & [7] \\
\hline Aspergilllus flavus & $0.137(0.117-0.163)$ & - & \\
\hline Aspergillus tereus & $0.164(0.069-0.300)$ & - & \\
\hline Aspergillus nidulans & $0.188(0.009-0.300)$ & - & \\
\hline Cladosporium sp. & 0.052 & - & \\
\hline Ahernaria sp. & $0.056(0-0.205)$ & - & \\
\hline Fusarium sp. & $0.023(0-0.059)$ & - & \\
\hline \multirow[t]{2}{*}{ Neocallimastix frontalis } & $0.067 \mathrm{U} / \mathrm{mg}$ & $0.132 \mathrm{U} / \mathrm{mg}$ & [35] \\
\hline & - & 0.32 & [33] \\
\hline Penicillium janthinellum & $0.360(0.24-0.55)$ & - & [36] \\
\hline \multirow[t]{2}{*}{ Penicillium sp. } & $0.078(0-0.139)$ & - & [7] \\
\hline & 0.973 & - & [37] \\
\hline Rhizopus sp. & $0.103(0-0.222)$ & - & [7] \\
\hline Trichoderma harziamum & 0.034 & - & \\
\hline Trichoderma longibrachiatum & 0.059 & - & \\
\hline \multirow[t]{2}{*}{ Trichoderma reesei } & $0.25 \pm 0.05 \mathrm{U} / \mathrm{mg}$ & $0.11 \pm 0.03 \mathrm{U} / \mathrm{mg}$ & [30] \\
\hline & - & $0.39 \pm 0.004$ & [34] \\
\hline \multirow[t]{2}{*}{ Trichoderma viride } & $0.63(0.28-1.00)$ & - & [36] \\
\hline & - & $0.016 \mathrm{U} / \mathrm{mg}$ & [38] \\
\hline $\begin{array}{l}\text { Fungal strain \#58 } \\
\text { (Meyerozyma sp.) }\end{array}$ & $\begin{array}{c}0.376 \\
0.179 \mathrm{U} / \mathrm{mg}\end{array}$ & $\begin{array}{c}0.209 \\
0.126 \mathrm{U} / \mathrm{mg}\end{array}$ & This study \\
\hline
\end{tabular}


from environmental airborne-fungal-spore samples. The $M c$-CBHI could remain fairly stable after 4-hr incubation at acid condition ( $\mathrm{pH} 3-5)$ and wide temperature range even at high temperature $\left(70^{\circ} \mathrm{C}-80^{\circ} \mathrm{C}\right)$. Additionally, it had specific FPase and avicelase activities of $0.179 \mathrm{U} / \mathrm{mg}$ and $0.126 \mathrm{U} / \mathrm{mg}$, respectively, which were about $40 \%-50 \%$ of a commercial cellulase Accellerase-1000 ( $0.44 \pm 0.01$ and $0.25 \pm 0.01 \mathrm{U} / \mathrm{mg})$. These results demonstrated that the newly-found $\mathrm{Mc}$-CBHI from Meyerozyma sp. had high stability and specific activity and could be a potential exoglucanase resource.

\section{Acknowledgements}

This study was supported by a fund from the National Science Council (NSC) of Taiwan (NSC 101-2221-E264-004-). We would like to thank Academician Ho David T.H. of the Institute of Plant and Microbial Biology of Academia Sinica for providing supports for PAGE and zymogram analyses and amino acid sequencing. We also appreciate Dr. Huang C.-Y. of the Department of Environmental Science and Engineering and Dr. Chuang M.-D. of the Department of Chemistry of Tunghai University for sharing laboratory space and equipments for fungal strain cultivations and enzyme activity tests.

\section{References}

[1] Tian, C., Zheng, L., Miao, Q., Cao, C. and Ni, Y. (2014) Improving the Reactivity of Kraft-Based Dissolving Pulp for Viscose Rayon Production by Mechanical Treatments. Cellulose, 21, 3647-3654. http://dx.doi.org/10.1007/s10570-014-0332-1

[2] Rubin, E.M. (2008) Genomics of Cellulosic Biofuels. Nature, 454, 841-845. http://dx.doi.org/10.1038/nature07190

[3] Kuhad, R.C., Gupta, R. and Singh, A. (2011) Microbial Cellulases and Their Industrial Applications. Enzyme Research, 2011, Article ID: 280696. http://dx.doi.org/10.4061/2011/280696

[4] Lynd, L.R., Weimer, P.J., van Zyl, W.H. and Pretorius, I.S. (2002) Microbial Cellulose Utilization: Fundamentals and Biotechnology. Microbiology and Molecular Biology Reviews, 66, 506-577. http://dx.doi.org/10.1128/MMBR.66.3.506-577.2002

[5] Kaur, B., Cberoi, H.S. and Chadha, B.S. (2014) Enhanced Cellulase Producing Mutants Developed from Heterokaryotic Aspergillus Strain. Bioresource Technology, 156, 100-107. http://dx.doi.org/10.1016/j.biortech.2014.01.016

[6] Saini, R., Saini, J.K., Adsul, M., Patel, A.K., Mathur, A., Tuli, D. and Singhania, R.R. (2015) Enhance Cellulase Production by Penicillium oxalicum for Bio-Ethanol Application. Bioresource Technology, 188, 240-246. http://dx.doi.org/10.1016/j.biortech.2015.01.048

[7] Jahangeer, S., Khan, N., Sohail, M., Jahangeer, S., Sohail, M., Shahzad, S., Ahmad, A. and Khan, S.A. (2005) Screening and Characterization of Fungal Cellulases Isolated from the Native Environmental Source. Pakistan Journal of Botany, 37, 739-748.

[8] Dar, R.A., Saba, I., Shahnawaz, M., Sangale, M.K., Ade, A.B., Rather, S.A. and Qazi, P.H. (2013) Isolation, Purification and Characterization of Carboxymethyl Cellulase (CMCase) from Endophytic Fusarium oxysporum Producing Podophyllotoxin. Advances in Enzyme Research, 1, 91-96. http://dx.doi.org/10.4236/aer.2013.14010

[9] Boyce, A. and Walsh, G. (2015) Characterisation of a Novel Thermostable Endoglucanase from Alicyclobacillus vulcanalis of Potential Application in Bioethanol Production. Applied Microbiology and Biotechnology. http://dx.doi.org/10.1007/s00253-015-6474-8

[10] Sapra, R., Park, J.I., Dalta, S. and Simmons, B.A. (2011) Novel Thermophilic Cellobiohydrolases. US Patent No. 20110207182 A1.

[11] Brevnova, E.E. (2013) Isolation and Characterization of Schizochytrium aggregatum Cellobiohydrolases I (Cbh 1). US Patent No. 8470592 B2.

[12] Yu, S.-M., Ho, T.H.D., Kuo, H.-W., Wu, N.I.S., Li, C.-W. and Ju, Y.-M. (2013) Beta-Glucosidase and Uses Thereof. US Patent No. 8394619 B1.

[13] Kausar, H., Sariah, M., Saud, H.M., Alam, M.Z. and Ismail, M.R. (2010) Development of Compatible Lignocellulolytic Fungal Consortium of Rapid Composting of Rice Straw. International Biodeterioration \& Biodegradation, 64, 594600. http://dx.doi.org/10.1016/j.ibiod.2010.06.012

[14] Khokhar, I., Haider, M.S., Mushtaq, S. and Mukhtar, I. (2012) Isolation and Screening of Highly Cellulolytic Filamentous Fungi. Journal of Applied Sciences and Environmental Management, 16, 223-226.

[15] Ja'afaru, M.I. (2013) Screening of Fungi Isolated from Environmental Samples for Xylanase and Cellulase Production. ISRN Microbiology, 2013, Article ID: 283423. http://dx.doi.org/10.1155/2013/283423 
[16] Sivaramanan, S. (2014) Isolation of Cellulolytic Fungi and Their Degradation on Cellulosic Agricultural Wastes. Journal of Academia and Industrial Research, 2, 458-463.

[17] Horner, W.E., Helbling, A., Salvaggio, J.E. and Lehrer, S.B. (1995) Fungal Allergens. Clinical Microbiology Reviews, 8, 161-179.

[18] Kostylev, M. and Wilson, D. (2012) Synergistic Interactions in Cellulose Hydrolysis. Biofuels, 3, 61-70. http://dx.doi.org/10.4155/bfs.11.150

[19] Kim, I.J., Lee, H.J., Choi, I.-G. and Kim, K.H. (2014) Synergistic Proteins for the Enhanced Enzymatic Hydrolysis of Cellulose by Cellulase. Applied Microbiology and Biotechnology, 98, 8469-8480. http://dx.doi.org/10.1007/s00253-014-6001-3

[20] Larkin, M.A., Blackshields, G., Brown, N.P., Chenna, R., McGettigan, P.A., McWilliam, H., Valentin, F., Wallace, I.M., Wilm, A., Lopez, R., Thompson, J.D., Gibson, T.J. and Higgins, D.G. (2007) Clustal W and Clustal X Version 2.0. Bioinformatics, 23, 2947-2948. http://dx.doi.org/10.1093/bioinformatics/btm404

[21] Page RDM (1996) TreeView: An Application to Display Phylogenetic Trees on Personal Computers. Computer Applications in the Biosciences, 12, 357-358.

[22] Hoefer Inc. (1994) Protein Electrophoresis Applications Guide. Hoefer Scientific Instruments, San Francisco.

[23] Yamanaka, R., Soares, C.F., Matheus, D.R. and Machado, K.M.G. (2008) Lignolytic Enzymes Produced by Trametes villosa CCB176 under Different Culture Conditions. Brazilian Journal of Microbiology, 39, 78-84. http://dx.doi.org/10.1590/S1517-83822008000100019

[24] Liu, D.Y., Li, J., Zhao, S., Zhang, R.F., Wang, M.M., Miao, Y.Z., Shen, Y.F. and Shen, Q.R. (2013) Secretome Diversity and Quantitative Analysis of Cellulolytic Aspergillus fumigates Z5 in the Present of Different Carbon Sources. Biotechnology for Biofuels, 6, 149. http://dx.doi.org/10.1186/1754-6834-6-149

[25] Ntougias, S., Bourtzis, K. and Tsiamis, G. (2013) The Microbiology of Olive Mill Wastes. BioMed Research International, 2013, Article ID: 784591. http://dx.doi.org/10.1155/2013/784591

[26] Nakayan, P., Hameed, A., Singh, S., Young, I.S. and Young, C.C. (2013) Phosphate-Solubilizing Soil Yeast Meyerozyma guilliermondii CC1 Improves Maize (Zea mays L.) Productivity and Minimizes Requisite Chemical Fertilization. Plant and Soil, 373, 301-315. http://dx.doi.org/10.1007/s11104-013-1792-z

[27] Kim, J.-S., Baek, J.-H., Park, N.-H. and Kim, C. (2015) Complete Genome Sequence of Halophilic Yeast Meyerozyma caribbica MG20W Isolated from Rhizosphere Soil. Genome Announcements, 3, Article ID: e00127-15. http://dx.doi.org/10.1128/genomeA.00127-15

[28] Kim, B.-K., So, J.-H. and Rhee, I.-K. (2011) Molecular Cloning and Functional Expression of an Extracellular Exo$\beta$-(1,3)-Glucanase from Candida fermentati Si. EMBL/GenBank/DDBJ Databases and Universal Protein Resource (UniProt) Databases. http://www.uniprot.org/uniprot/G5DE31

[29] Takada, G., Kawaguchi, T., Sumitani, J. and Arai, M. (1998) Cloning, Nucleotide Sequence, and Transcriptional Analysis of Aspergillus aculeatus No. F-50 Cellobiohydrolase I (cbhI) Gene. Journal of Fermentation and Bioengineering, 85, 1-9. http://dx.doi.org/10.1016/S0922-338X(97)80345-5

[30] Fujii, T., Fang, X., Inoue, H., Murakami, K. and Sawayama, S. (2009) Enzymatic Hydrolyzing Performance of Acremonium cellulolyticus and Trichoderma reesei against Three Lignocellulosic Materials. Biotechnology for Biofuels, 2, 24. http://dx.doi.org/10.1186/1754-6834-2-24

[31] Howard, R.L., Abotsi, E., Jansen van Rensburg, E.L. and Howard, S. (2003) Lignocellulose Biotechnology: Issues of Bioconversion and Enzyme Production. African Journal of Biotechnology, 2, 602-619. http://dx.doi.org/10.5897/AJB2003.000-1115

[32] Gao, L., Gao, F., Wang, L.S., Geng, C.L., Chi, L.L., Zhao, J. and Qu, Y.B. (2012) N-Glycoform Diversity of Cellobiohydrolase I from Penicillium decumbens and Synergism of Nonhydrolytic Glycoform in Cellulose Degradation. The Journal of Biological Chemistry, 287, 15906-15915. http://dx.doi.org/10.1074/jbc.M111.332890

[33] Mountfort, D.O. and Asher, R.A. (1985) Production and Regulation of Cellulase by Two Strains of the Rumen Anaerobic Fungus Neocallimastix frontalis. Applied and Environmental Microbiology, 49, 1314-1322.

[34] Boer, H. and Koivula, A. (2003) The Relationship between Thermal Stability and pH Optimum Studied with WildType and Mutant Trichoderma reesei Cellobiohydrolase Cel7A. European Journal of Biochemistry, 207, 841-848. http://dx.doi.org/10.1046/j.1432-1033.2003.03431.x

[35] Li, X.L. and Calza, R.E. (1991) Fractionation of Cellulases from the Ruminal Fungus Neocallimastix frontalis EB188. Applied and Environmental Microbiology, 57, 3331-3336.

[36] Adsul, M.G., Ghule, J.E., Singh, R., Shaikh, H., Bastawde, K.B., Gokhale, D.V. and Varma, A.J. (2004) Polysaccharides from Bagasse: Applications in Cellulase and Xylanase Production. Carbohydrate Polymers, 57, 67-72. http://dx.doi.org/10.1016/j.carbpol.2004.04.001 
[37] Hao, J.J., Tian, X.J., Song, F.Q., He, X.B., Zhang, Z.J. and Zhang, P. (2006) Involvement of Lignocellulolytic Enzymes in the Decomposition of Leaf Litter in a Subtropical Forest. The Journal of Eukaryotic Microbiology, 53, $193-$ 198. http://dx.doi.org/10.1111/j.1550-7408.2006.00093.x

[38] Beldman, G., Searle-van Leeuwen, M.J., Rombouts, F.M. and Voragen, F.G.J. (1985) The Cellulase of Trichoderma viride-Purification, Characterization and Comparison of All Detectable Endoglucanases, Exoglucanases and $\beta$ Glucosidases. European Journal of Biochemistry, 146, 301-308. http://dx.doi.org/10.1111/j.1432-1033.1985.tb08653.x 